\title{
Differentiating Between Malignant and Benign Breast Masses: Factors Limiting Sonoelastographic Strain Ratio
}

\author{
Wertigkeit der semiquantitativen Sonoelastografie (Strain Ratio) in der \\ Differenzierung maligner von benignen Brusttumoren
}

Authors

Affiliations
A. Stachs ${ }^{1}$, S. Hartmann ${ }^{1}$, J. Stubert ${ }^{1}$, M. Dieterich ${ }^{1}$, A. Martin ${ }^{1}$, G. Kundt ${ }^{2}$, T. Reimer ${ }^{1}$, B. Gerber ${ }^{1}$

Department of Obstretrics and Gynecology, University of Rostock Medical School

Department of Biostatistics, University of Rostock

\author{
Key words \\ - breast \\ - elastography \\ - strain ratio \\ - ultrasound \\ - specificity
}

$\begin{array}{ll}\text { received } & 25.5 .2012 \\ \text { accepted } & 25.7 .2012\end{array}$

\section{Bibliography}

Dol http://dx.doi.org/

10.1055/s-0032-1313168

Published online: October 29,

2012

Ultraschall in Med 2013; 34:

131-136 @ Georg Thieme

Verlag KG Stuttgart - New York .

ISSN 0172-4614

\section{Correspondence \\ Dr. Angrit Stachs}

Department of Obstretrics and Gynecology, University of

Rostock Medical School

Südring 81

18059 Rostock

Germany

Tel.: ++ 49/3 81/44018463

Fax: ++ 49/3 81/44015599

angrit.stachs@med.uni-rostock. de

\section{Zusammenfassung}

$\nabla$

Ziel: Ermittlung des Stellenwerts der semiquantitativen Strain Ratio (SR) in der Dignitätsbeurteilung von Mammatumoren unter Berücksichtigung limitierender Faktoren

Material und Methoden: 215 Patientinnen mit 224 Brusttumoren wurden vor Stanzbiopsie mit einem Stufe-3-Ultraschallgerät mit serieller Elastografieausstattung untersucht. Die Einschätzung des Elastizitätsscores (ES) und Ermittlung der SR erfolgten patientenunabhängig anhand gespeicherter Rohdatensätze. Die diagnostische Aussagekraft wurde durch Receiver-Operating-Characteristics (ROC)-Analyse ermittelt, eine Subgruppenanalyse hinsichtlich Brustdichte, Tumorgröße und Hautabstand erfolgte.

Ergebnisse: Die 116 malignen Tumoren wiesen eine signifikant größere mittlere SR auf als die 108 benignen Tumoren $(3,04 \pm 0,9$ vs. $1,91 \pm 0,75$; $\mathrm{p}<0,001)$. Die ROC-Analyse ergab für die SR einen AUC(area under the curve)-Wert von 0,832 (95\% Cl $0,777 ; 0,888)$, für den ES 0,869 (95\% CI 0,822; 0,917 ) und für die B-Mode-Sonografie 0,822 (95\% CI 0,$768 ; 0,876)$. Unter Nutzung eines Cut-offWertes von 2,0 weist die SR eine Sensitivität von $90,7 \%$ und eine Spezifität von 58,2\% auf (ES 87,9\% und 73,1\%, B-Mode-Sonografie 97,4\% und 42,6\%). Die Multivarianzanalyse zum Einfluss von Brustdichte, Tumorgröße und Hautabstand zeigt eine negative Korrelation zwischen Hautabstand und Genauigkeit der SR.

Schlussfolgerung: Beide Elastografieverfahren zeigen im Vergleich zur B-Mode-Sonografie eine höhere Spezifität bei etwas geringerer Sensitivität. Bei oberflächlich gelegenen Tumoren ist die SR limitiert verwertbar.

\section{Abstract \\ $\nabla$}

Purpose: We compared strain ratio vs. qualitative elastography for the further differentiation of focal breast lesions, with special focus on limiting factors.

Materials and Methods: 215 patients with 224 histologically proven breast masses (116 malignant, 108 benign) were prospectively examined using a high-end ultrasound system (Philips iU22) with serial elastography function. B-mode scans and available mammograms were reviewed according to the BIRADS classification, raw elastogram data was analyzed qualitatively using the Tsukuba score and semiquantitatively by calculating the strain ratio (fat to lesion ratio). For diagnostic performance, Receiver Operating Characteristic (ROC) curve analysis was obtained. A sub-group analysis regarding breast density, lesion size, lesion depth and histological subtypes was performed.

Results: Mean strain ratio values were $3.04 \pm 0.9$ for malignant and $1.91 \pm 0.75$ for benign lesions $(\mathrm{p}<0,001)$. The areas under the ROC curve values were 0.832 (95\% CI $0.777 ; 0.888)$ for strain ratio, 0.869 (95\% CI $0.822 ; 0.917)$ for Tsukuba score, 0.822 ( $95 \%$ CI 0.768 ; 0.876) for B-mode ultrasound and 0.853 (95\% CI 0.799; 0.907) for mammography. Sensitivity, specificity, positive predictive value and negative predictive value of the strain ratio were $90.7 \%, 58.2 \%, 70.3 \%$ and $85.1 \%$, when a cutoff point of 2.0 was used. Only lesion depth $\leq 4 \mathrm{~mm}$ was associated with diagnostic failure in the multivariate analysis of factors influencing accuracy, whereas no significant correlation between breast density and lesion size and the accuracy of the strain ratio could be found.

Conclusion: The addition of strain ratio to B-mode ultrasound increases specificity without loss of sensitivity in differentiating between malignant and benign breast tumors. Strain ratio measurements should not be carried out on tumors with a lesion depth $\leq 4 \mathrm{~mm}$. 


\section{Introduction}

$\nabla$

Over the last 20 years, sonoelastography has developed from a technically complex examination method to one that is simple to carry out and reproduce, and that can be integrated into clinical examination procedures [1]. Various manufacturers of ultrasound devices have integrated elastography as a standard feature, and its use in a range of clinical settings is the subject of numerous current studies [2-5]. Previous studies have provided evidence for the benefits of sonoelastography as an additional procedure in breast ultrasound [6-11]. A 5-stage elasticity score has been established by Ueno et al. as the standard in elastography evaluation [12]. However, the use of this score requires a certain amount of experience; the interobserver and intraobserver variability is considerable [13]. The calculation of the strain ratio is a semi-quantitative measurement that indicates the average deformation of a lesion in relation to the deformation in a reference region (usually the lateral, surrounding fatty tissue) [14]. The measurement results in a metric value with no specified dimensions. More recent studies have shown a significant difference between the average strain ratio of benign and malignant breast tumors [6, $15-18]$.

The aim of our study was to determine the value of strain ratio to discriminate between malignant and benign breast tumors in comparison to the qualitative 5-stage elasticity score and conventional B-mode ultrasound. Secondary study aim was to investigate factors that limit the use of sonoelastography.

\section{Materials and Methods}

$\nabla$

\section{Patients}

Between January 2010 and October 2010, a total of 215 patients with 224 breast masses were prospectively enrolled in the study. B-mode ultrasound was carried out on all patients, and mammograms were available for 190 patients. Mammography was not carried out on 25 patients due to their young age. After informed consent, real-time elastographic examination was carried out and the data sets were saved. Final diagnoses were made on the basis of histological findings. The local institutional review board approved the study.

\section{Data Acquisition/Imaging Methods}

Conventional ultrasound images and real-time elastographic data sets were obtained from three very experienced ultrasound examiners using a 12.5-MHz linear transducer (Philips iU22, Bothell, WA, USA). The principles of ultrasound real-time elastography are well-known $[12,19,20]$. The sonoelastographic function of the Philips software is based on tissue compression during thoracic respiratory excursions. In order to obtain appropriate images, the transducer has to be applied with only the light pressure necessary to maintain contact with the skin. The results are displayed as color-coded images, with blue representing hard tissue and red to green representing soft tissue on a continuous scale ( $\bullet$ Fig. 1). In addition, for semi-quantitative evaluation of the strain ratio, a 60-second cineloop was obtained during elastographic examination. The strain ratio describes the fat to lesion ratio, indicating the stiffness of a lesion. It is obtained by setting a rectangular Region of Interest (ROI) to cover the subcutaneous fatty tissue and a second ROI to cover the lesion. The Philips iU22 software package features the possibility of retrospectively analyzing the strain ratio (known as „deformation quotient”). The cineloop can be used to create a deformation quotient curve, which can in turn be used to calculate the mean and maximum deformation quotients ( $\bullet$ Fig. 2 ).

All acquired data were reviewed by an experienced ultrasound examiner. The B-mode images were evaluated according to the Breast Imaging Reporting and Data System (BIRADS) classification. BIRADS categories 1 to 3 were assumed to be benign, and BIRADS categories 4 and 5 were taken as malignant. The elastographic data sets were analyzed qualitatively using the Tsukuba elasticity score. This is a color-coded 5-stage score with score 1 revealing the whole lesion in green and score 5 revealing the lesion and its surrounding tissue in blue. Lesions categorized as score 1, 2 or 3 are assumed to be benign, while lesions categorized as score 4 or 5 are assumed to be malignant. Further details can be found elsewhere [12].

In order to carry out a semi-quantitative elastographic evaluation, the strain ratio of the lesions was obtained. According to the user manual, the most appropriate single image should be selected for further analysis. Since we observed significant intraobserver variability, the following protocol was used: All measurements (setting the ROIs) were carried out three times. A mean was calculated from the three results for mean deformation quotient as well as maximum deformation quotient. This procedure

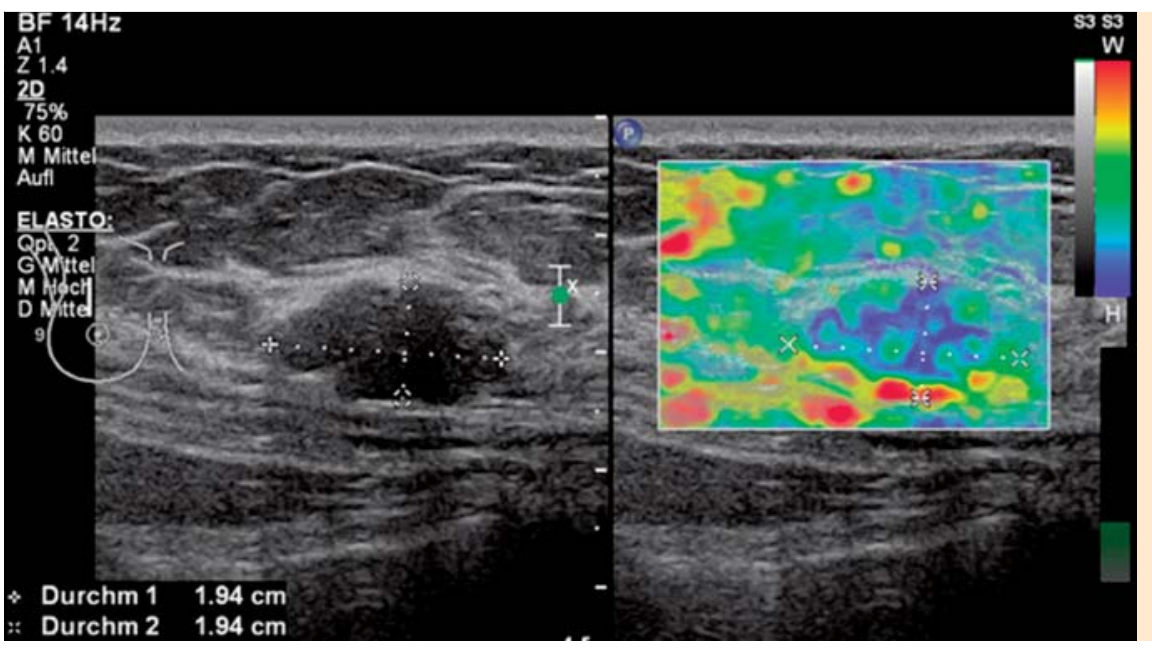

Fig. 1 Ultrasound and elastography images of a benign fibroadenoma. B-mode ultrasound images showing a lobulated mass with fuzzy margins according to category 4 of BIRADS classification. Elastography image showing high peripheral strain that corresponds to Score 3 of a 5-point elasticity score (Tsukuba score).

Abb. 1 Sonografischer Befund eines Fibroadenoms. Im B-Bild lobulierter echoarmer Herd mit partiell unscharfer Begrenzung entsprechend einer BIRADS-4-Läsion. Das Elastogramm zeigt eine hohe periphere Dehnbarkeit (grün) sowie zentral wenig elastische Anteile (blau gefärbte Areale) und entspricht einem Tsukuba-Elastizitätsscore von 3. 


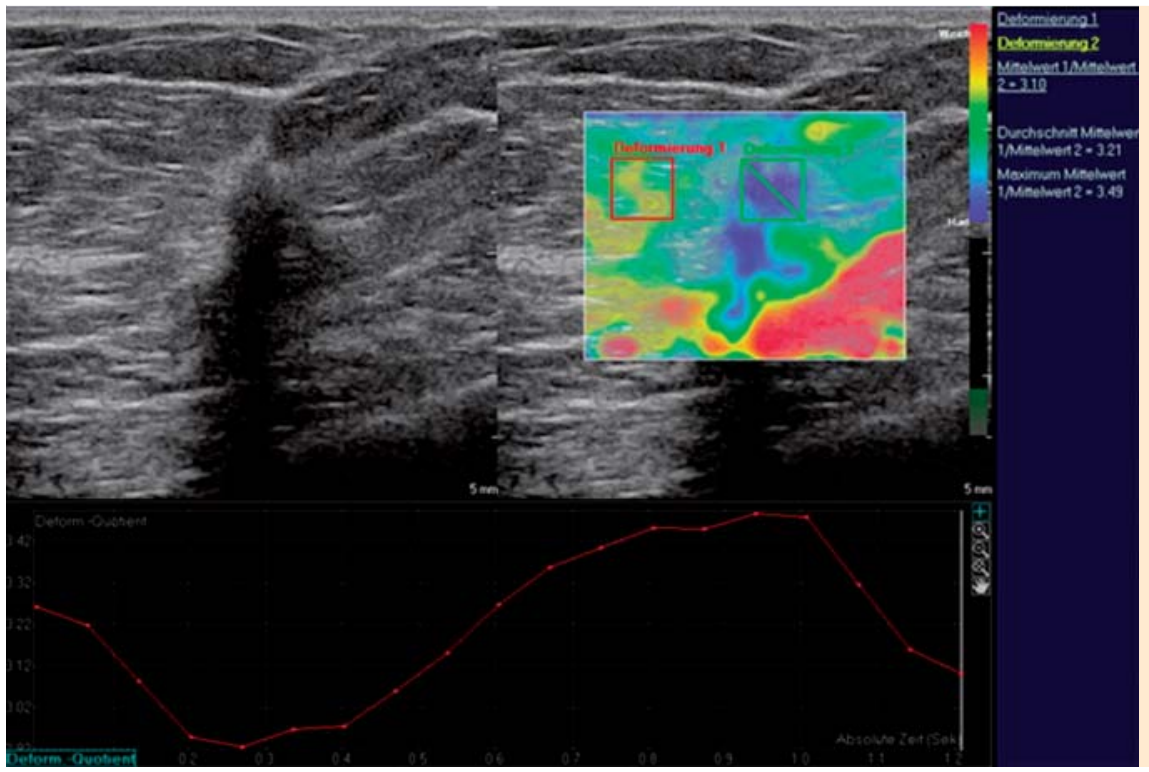

Fig. 2 Strain ratio (SR) analysis. SR is determined by calculating the strain measured in the adjacent fatty tissue and the strain measured in the lesion. The strain ratio reflects the relative stiffness of a lesion. High strain ratio levels indicate an increasing probability of malignancy.

Abb. 2 Berechnung der Strain Ratio (SR). Durch Platzierung einer rechteckigen Region of Interest (ROI) in das umgebende Fettgewebe (= Deformierung 1) sowie einer zweiten ROI in die Läsion (Deformierung 2) wird das Verhältnis der Elastizität beider Gewebe (= Deformationsquotient) abgebildet. Hohe SR-Werte reflektieren eine hohe Gewebesteifigkeit der Läsion und sind mit einer höheren Wahrscheinlichkeit eines malignen Befunds assoziiert.

was carried out with a single image, with a sequence of 20 images, and with the entire cineloop (60 images).

\section{Statistics}

Statistical analysis was carried out in collaboration with an independent statistician (G. K.) using the SPSS 19.0 software package (IBM Ehningen, Germany). First, descriptive statistics were computed for variables of interest. The statistics computed included mean, median, minimum, maximum and standard deviations of continuous variables, frequencies and percentage frequencies of categorical factors. Additionally, 95\% confidence intervals are presented. Furthermore, comparison of the strain ratio means between benign and malignant masses was realized by using Student $t$ test. In order to further evaluate the performance of strain ratio in the differentiation between benign and malignant lesions, a Receiver Operating Characteristic (ROC) analysis was carried out to compare the area under the curve (AUC). The best results were obtained using the mean strain ratio of the sequence image analysis, so these data were used for further evaluation. The diagnostic sensitivity, specificity, positive and negative predictive values and accuracy were calculated for the qualitative elasticity score and the strain ratio in comparison with mammography and conventional ultrasound. Finally, we compared the diagnostic properties of the strain ratio according to lesion size, distance from the skin (lesion depth), breast density and histological subtypes. All p-values resulted from two-sided statistical tests and $\mathrm{p} \leq 0.05$ was considered to be significant.

\section{Results}

\section{Study population}

The patients' median age was 56 years, with a range of 12 to 90 years. Of the 224 lesions, 116 (51.8\%) were malignant and 108 ( $48.2 \%$ ) were benign. The lesion size ranged from 4 to $110 \mathrm{~mm}$ with a median of $15 \mathrm{~mm}$. There were 125 (55.8\%) palpable masses among the study population. Concerning breast density, $10 \%$ revealed fatty tissue, $47 \%$ scattered fibroglandular tissue, $35 \%$ heterogeneously dense tissue and $8 \%$ extremely dense tissue.

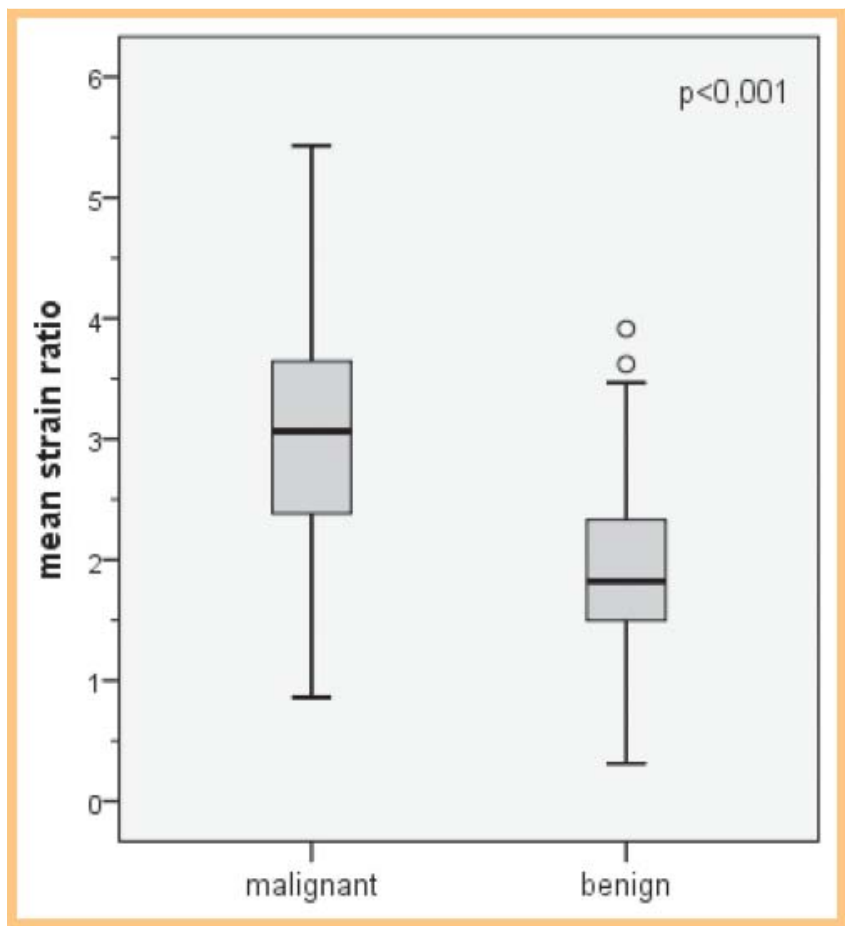

Fig. 3 Boxplot graphs demonstrate the significant difference in the strain ratio values between malignant $(n=116)$ and benign $(n=108)$ breast lesions.

Abb. 3 Boxplot-Diagramm der Strain Ratio (SR) von malignen $(n=116)$ und benignen ( $n=108)$ Mammabefunden. Die Differenz ist hochsignifikant.

\section{Strain ratio}

The mean strain ratio for malignant breast tumors was $3.04 \pm 0.9$ (mean \pm standard deviation SD, range 0.86 to 5.43 ) and was significantly higher than for benign breast tumors $(1.91 \pm 0.75$, range 0.31 to 3.91 ) ( $\bullet$ Fig. 3 ). $\bullet$ Fig. 4 shows the diagnostic performance of the strain ratio using the ROC curve. At a cutoff of $\leq 2.0$ for benign tumors and $>2.0$ for malignant tumors, sensitivity was $90.7 \%$ (95\% CI 83.6\%; $94.8 \%$ ), specificity was 59.2\% (95\% CI $48.3 \%$; $67.4 \%$ ), the positive predictive value (PPV) was $70.3 \%$ 


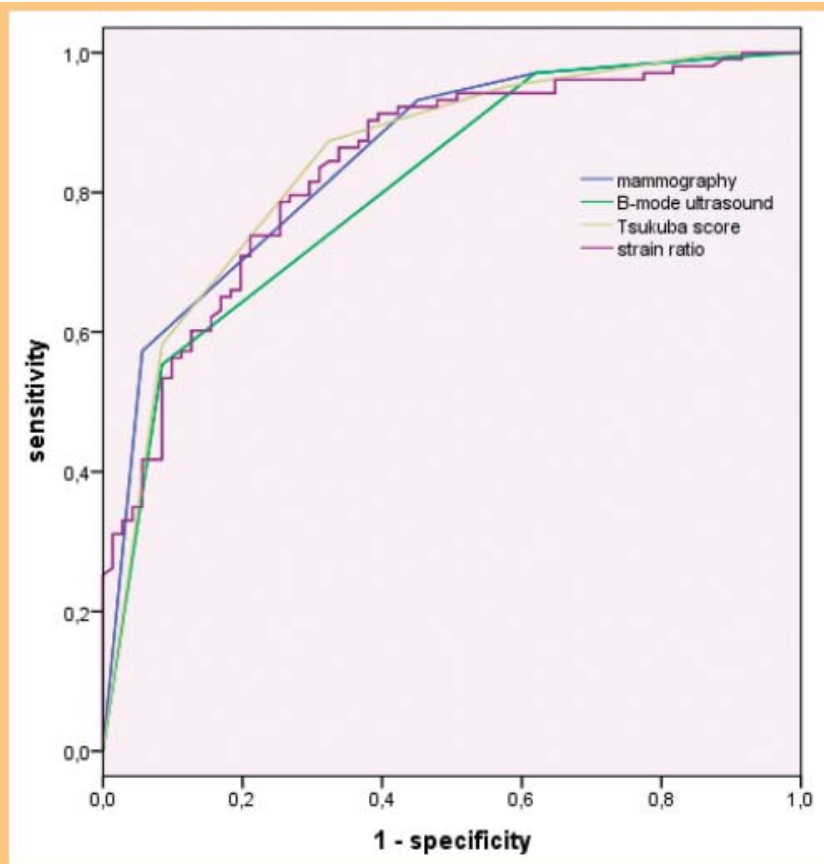

Fig. 4 Receiver Operating Characteristics (ROC) curves for the sonoelastographic strain ratio, the Tsukuba elasticity score, B-mode ultrasound and mammography. The AUC values did not vary significantly between the imaging methods.

Abb. 4 Diagnostische Performance der Strain Ratio, des Tsukuba-Elastizitätsscores, des B-Mode-Ultraschalls und der Mammografie, dargestellt mittels Receiver-Operating-Characteristics(ROC)-Kurven. Die Area-Underthe-Curve(AUC)-Werte weisen keinen signifikanten Unterschied auf.

(95\% CI $62.2 \% ; 77.3 \%$ ), the negative predictive value was $85.1 \%$ (95\% Cl 74.7\%; $91.7 \%)$ and accuracy was $75.1 \%(95 \%$ CI 69.2; 81).

\section{Diagnostic Performance in Comparison to Mammo- graphy, B-mode Ultrasound and Qualitative Sonoelas- tography (5-point scale)}

- Table 1 shows the sensitivity, specificity, PPV, NPV and accuracy in comparison to conventional methods (mammography and B-mode ultrasound) and to qualitative sonoelastography using a 5-point scale ( $1-3$ benign, $4-5$ malignant).

Although the sensitivity of elastography is lower than for B-mode ultrasound, it provides higher specificity. At $80.8 \%$, qualitative sonoelastography provides the greatest accuracy.

If we consider the sub-group with BIRADS 4 in B-mode ultrasound, this results in a pretest probability for a malignant tumor of $48 \%$; after including sonoelastography for scale $1-3 /$ strain ratio $\leq 2.0$, this results in a posttest probability of $25 \% / 25.8 \%$; and for scale $4-5 /$ strain ratio $>2.0$, this results in a posttest probability of $67.2 \% / 56.9 \%$.

\section{Strain Ratio Depending on Tumor Size, Distance from Skin, Breast Density and Histological Diagnosis} The extent to which the predictive accuracy of strain ratio depends on external factors was investigated using bivariate correlation analysis. The analysis shows a statistically significant negative correlation between the distance of the tumor from the surface of the skin and the correct estimation of whether the tu-

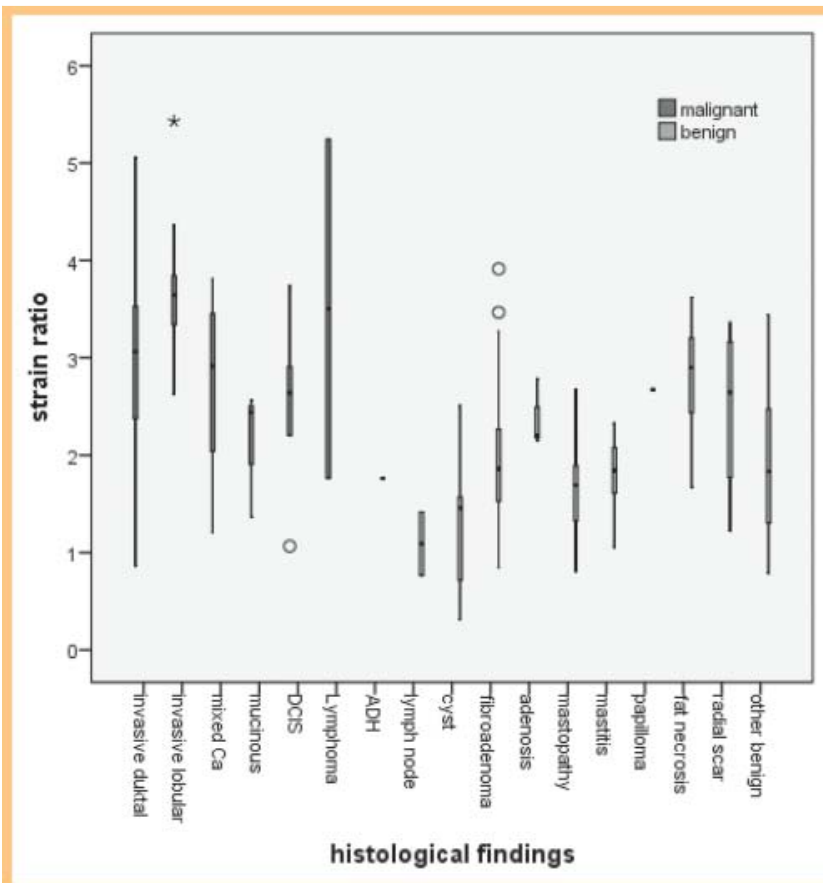

Fig. 5 Boxplot graphs demonstrate strain ratio values according to histologic subclassification. DCIS = Ductal Carcinoma in Situ, ADH = Atypical Ductal Hyperplasia.

Abb.5 Boxplot-Diagramm der SR in Abhängigkeit von der histologischen Diagnose. DCIS = duktales Carcinoma in situ, $A D H=$ atypische duktale Hyperplasie.

mor is malignant or benign ( $p=0.038$ ). If we compare the group of tumors located close to the surface (skin distance $\leq 4 \mathrm{~mm}$ ) with deeper lesions (skin distance $>4 \mathrm{~mm}$ ), the latter group displays considerably higher sensitivity (94.2 vs. $75 \%$ ) and specificity (61.5 vs. $48.4 \%)$.

Breast density and tumor size did not influence the diagnostic performance of the strain ratio.

- Fig. 5 shows the average strain ratio of the various histological diagnoses. It is shown that for malignancies, the average strain ratio is considerably higher than for benign histologies. Particularly, this applies to invasive lobular breast carcinomas (mean 3.69; range $2.62-5.43 ; n=10$ ), which are often difficult to judge using mammography and sonography. Of the benign tumors, fatty necrosis (mean 2.78; range $1.67-3.62 ; n=7$ ) and radial scars (mean 2.46: range $1.22-3.36 ; n=4$ ) show a high strain ratio.

The diagnostic accuracy of the various methods (mammography, B-mode ultrasound, 5-point scale sonoelastography and strain ratio) in the different histological categories is shown in 0 Table 2. Of the malignant tumors, mucinous breast carcinoma is not identified as malignant by sonoelastography (5-point scale) (0/3) and is identified as malignant by strain ratio in $2 / 3$ cases. In identifying cysts as benign, sonoelastography outperforms B-mode ultrasound (5-point scale elastography 9/11, strain ratio 10/11, Bmode ultrasound 5/11). In all examination methods, fat necrosis and radial scars represent a diagnostic challenge. 
Table 1 Diagnostic performance of strain ratio and 5-point score elastography (Tsukuba score) vs. B-mode ultrasound and mammography.

\begin{tabular}{|lllll|} 
& strain ratio & 5-point score elastography & B-mode Ultrasound & mammography \\
\hline sensitivity (\%) & $90.7(83.6-94.8)$ & $87.9(80.8-92.7)$ & $97.4(92.7-99.1)$ & $92.9(86.5-96.3)$ \\
\hline Specificity (\%) & $58.2(48.3-67.4)$ & $73.1(64.1-80.6)$ & $42.6(33.7-52)$ & $56.4(45.4-66.9)$ \\
\hline PPV (\%) & $70.3(62.2-77.3)$ & $77.9(70-84.1)$ & $64.6(57.2-71.3)$ & $75.4(67.6-81.8)$ \\
\hline NPV (\%) & $85.1(74.7-91.7)$ & $84.9(76.3-90.8)$ & $93.9(83.5-97.9)$ & $84.6(72.5-92)$ \\
\hline accuracy (\%) & $75.1(69.2-81)$ & $80.8(75.4-86.2)$ & $71(65.1-76.9)$ & $77.9(72-83.8)$ \\
\hline AUC & $0.83(0.78-0.89)$ & $0.87(0.82-0.92)$ & $0.82(0.77-0.88)$ & $0.85(0.80-0.91)$ \\
\hline
\end{tabular}

1 Data presented as mean ( $95 \%$ confidence interval).PPV = Positive Predictive Value, NPV = Negative Predictive Value, AUC = Area Under the Curve.

\begin{tabular}{|c|c|c|c|c|c|c|c|c|}
\hline & \multicolumn{2}{|c|}{ strain ratio } & \multicolumn{2}{|c|}{ 5-point score elastography } & \multicolumn{2}{|c|}{ B-mode ultrasound } & \multicolumn{2}{|c|}{ mammography } \\
\hline & benign & malignant & benign & malignant & benign & malignant & benign & malignant \\
\hline IDC & 6 & 75 & 7 & 78 & 1 & 84 & 6 & 75 \\
\hline ILC & 0 & 10 & 0 & 13 & 0 & 13 & 1 & 12 \\
\hline IMC & 1 & 2 & 3 & 0 & 0 & 3 & 1 & 2 \\
\hline DCIS & 1 & 4 & 1 & 4 & 1 & 4 & 0 & 5 \\
\hline lymphoma & 1 & 1 & 1 & 1 & 1 & 1 & 0 & 2 \\
\hline $\mathrm{ADH}$ & 1 & 0 & 3 & 0 & 1 & 2 & 3 & 0 \\
\hline papilloma & 0 & 1 & 2 & 1 & 1 & 2 & 1 & 0 \\
\hline fibroadenoma & 27 & 18 & 35 & 11 & 26 & 20 & 13 & 13 \\
\hline cyst & 10 & 1 & 9 & 2 & 5 & 6 & 7 & 1 \\
\hline mastopathy & 6 & 2 & 8 & 2 & 4 & 6 & 7 & 3 \\
\hline fat necrosis & 1 & 6 & 2 & 5 & 0 & 7 & 3 & 3 \\
\hline radial scar & 1 & 3 & 1 & 3 & 0 & 4 & 0 & 4 \\
\hline
\end{tabular}

${ }^{1}$ IDC = Invasive Ductal Carcinoma, ILC = Invasive Lobular Carcinoma, IMC = Invasive Mucinous Carcinoma, DCIS = Ductal Carcinoma in Situ, ADH=Atypical Ductal Hyperplasia.

\section{Discussion}

\section{$\nabla$}

In the presented study, the raw data sets of the elastograms saved in DICOM format were retrospectively blinded and evaluated, and the strain ratio was calculated for each data set. However, integration into the current examination process does not seem to involve any problems and requires an additional time of approximately $2-3$ minutes. This corresponds to the experiences of other working groups [21].

Previous studies have shown the potential of elastography for differentiating between benign and malignant breast tumors $[6,8$, $16,23]$. Our study reveals a significant difference in the average strain ratio of benign and malignant lesions. At a cutoff value of $\leq 2.0$, both the strain ratio and the 5 -point score demonstrate a higher specificity and higher PPV than B-mode ultrasound and mammography, albeit with a slightly lower sensitivity. In terms of accuracy, 5-point score elastography was superior to the other examination methods. Other studies have demonstrated an increase in NPV with additional use of elastography [7, 18]. However, at an NPV of $85 \%$ for both elastography methods, histological findings for sonographically suspicious lesions must be verified. In a multi-center study by Wojcinski et al., the following algorithm was proposed for the implementation of sonoelastography: for B-mode ultrasound BIRADS category 3 findings with a negative elastogram (Tsukuba score $1-3$ ), histological diagnostic confirmation (core biopsy) is not required [8].

Our own results prove that strain ratio offers lower diagnostic validity for tumors located close to the surface of the skin. To our knowledge, these findings have not yet been described. In a study by Chang et al, breast thickness at the location of the target lesion was the most important factor influencing elasticity image qual- ity. In univariate analysis, higher lesion depth and breast thickness as well as large tumor size were associated with low-quality elastograms, which in turn provided lower sensitivity than highquality elastograms [24]. In our study, we were unable to confirm the extent to which the diagnostic performance of strain ratio is dependent on the tumor size.

Strain ratio shows significant differences in the various histological entities. A good differentiation of malignant versus benign findings is achieved for invasive ductal carcinomas and invasive lobular carcinomas. The latter could be a valuable addition, as invasive lobular carcinoma is often insufficiently diagnosed when using conventional methods (mammography, B-mode ultrasound). For mucinous carcinomas, strain ratio outperforms 5point score elastography. However, the results must be interpreted with caution due to the low number of cases $(n=3)$. In contrast to the study by Mori [25], our own data supports that the elastography score is not suitable for differentiating between mucinous breast carcinomas and fibroadenomas.

In terms of false positive findings, the histological finding categories of fat necrosis and radial scars appear to be problematic. While fat necrosis is reliably diagnosed using mammography, radial scars remain a diagnostic challenge that, ultimately, can only be verified as benign by means of histological methods.

There are limitations in the retrospective design of the study and in the evaluation of the elastography data by just one investigator. It is not possible to provide data on interobserver variability. In addition, it is difficult to compare the results directly with other working groups as different cutoff values have been established for the strain ratio depending on the device [7, 16-18]. This means that, for the time being, strain ratio will continue to be implemented in the diagnostic algorithm for differentiating 
breast lesions on a center and device-specific basis. No general recommendation can be provided due to a lack of standardization in the examination process, including in the software required for computation.

„Shear wave ultrasound elastography“ facilitates quantitative measurement of tissue elasticity and represents an interesting development in this regard [23]. A recently published multi-center study by Berg et al. [26] showed that the addition of shear wave elastography to B-mode ultrasound improved specificity without reducing sensitivity. Moreover, shear wave elastography reveals a high intra- and interobserver reproducibility [27].

\section{Acknowledgment}

$\nabla$

We thank Katrin Herbst (Philips Healthcare GmbH Hamburg, Germany) for providing a native speaker for the correction of our manuscript.

\section{References}

1 Sarvazyan A, Hall TJ, Urban MW et al. An overview of elastography - an emerging branch of medical imaging. Curr Med Imaging Rev 2011; 7: $255-282$

2 Wells PN, Liang HD. Medical ultrasound: imaging of soft tissue strain and elasticity. J R Soc Interface 2011; 8: 1521 -1549

3 Balleyguier C, Canale S, Ben Hassen W et al. Breast elasticity: Prinziples, technique, results: an update and overview of commercially available software. Eur J Radiol 2012, Mar 24 [epub ahead of print]

4 Cho N, Moon WK, Park JS. Real-time US elastography in the differentiation of suspicious microcalcifications on mammography. Eur Radiol 2009; 19: $1621-1628$

5 Isermann R, Grunwald S, Hatzung G et al. Breast lesion sizing by Bmode imaging and sonoelastography in comparison to histopathological sizing - a prospective study. Ultraschall in Med 2011; 32: 21-26

6 Thomas A, Degenhardt F, Farrokh A. Significant differentiation of focal breast lesions. Calculation of strain ratio in breast sonoelastography. Acad Radiol 2010; 17: 558-563

7 Cho N, Moon WK, Kim HY et al. Sonoelastographic strain index for differentiation of benign and malignant nonpalpable breast masses. J Ultrasound Med 2010; 29: 1 -7

8 Wojcinski S, Farrokh A, Weber S et al. Multicenter study of ultrasound real-time tissue elastography in 779 cases for the assessment of breast lesions: improved diagnostic performance by combining the BIRADSUS classification system with sonoelastography. Ultraschall in Med 2010; 31: 484-491

9 Lee JH, Kim SH, Kang BJ et al. Role and clinical usefulness of elastography in small breast masses. Acad Radiol 2011; 18: 74-80
10 Sadigh G, Carlos RC, Neal CH et al. Ultrasonic differentiation of malignant from benign breast lesions: a meta-analytic comparison of elasticity and BIRADS scoring. Breast Cancer Res Treat 2011, Nov 5 (Epub ahead of print)

11 Schaefer FK, Heer I, Schaefer PJ et al. Breast ultrasound elastography results of 193 breast lesions in a prospective study with histopathologic correlation. Eur J Radiol 2011; 77: 450 - 456

12 Itoh A, Ueno E, Tohno E et al. Breast disease: clinical application of US elastography for diagnosis. Radiology 2006; 239: 341 - 350

13 Yoon JH, Kim MH, Kim EK et al. Interobserver variability of ultrasound elastography: how it affects the diagnosis of breast lesions. Am J Radiol 2011; 196: $730-736$

14 Zhi H, Xiao XY, Yang HY et al. Semi-quantitating stiffness of breast solid lesions in ultrasonic elastography. Acad Radiol 2008; 15: 1347-1353

15 Geaid M, Grunwald S, Hatzung G et al. Fat-lesion-ratio vs. elastography score: a new method for sonoelastography in the diagnostics of breast lesions. Ultraschall in Med 2008; 29: OP_2_15

16 Farrokh A, Wojcinski S, Degenhardt F. Diagnostic value of strain ratio measurements in the differentiation of malignant and benign breast lesions. Ultraschall in Med 2011; 32: 400-405

17 Zhi H, Xiao XY, Yang HY et al. Ultrasonic elastography in breast cancer diagnosis: strain ratio vs 5-point scale. Acad Radiol 2010; 17: 1227 1233

18 Fischer T, Peisker U, Fiedor $S$ et al. Significant differentiation of focal breast lesions: raw data-based calculation of strain ratio. Ultraschall in Med 2011, May 25. [Epub ahead of print]

19 Burnside ES, Hall TJ, Sommer AM et al. Differentiating benign from malignant solid breast masses with US strain imaging. Radiology 2007; 245: $401-410$

20 Zhu QL, Jiang YX, Liu JB et al. Real-time ultrasound elastography: its potential role in assessment of breast lesions. Ultrasound Med Biol 2008; 34: $1232-1238$

21 Wojcinski S, Farrokh A, Gyapong S et al. Sonoelastographie: Welche Verfahren gibt es? Wie sind Handhabung und Reproduzierbarkeit im klinischen Alltag? [Sonoelastography: What procedures exist? How is it used in clinical practice and how reproducible is it?]. Düsseldorf: In: Deutsche Gesellschaft für Senologie, 29. Jahrestagung; 2009

22 Hatzung G, Grunwald S, Zygmunt M et al. Sonoelastography in the diagnosis of malignant and benign breast lesions: initial clinical experiences. Ultraschall in Med 2010; 31: 596-603

23 Evans A, Whelehan P, Thomson K. Quantitative shear wave ultrasound elastography: initial experience in solid breast masses. Breast Cancer Research 2010; 12: R104

24 Chang JM, Moon WK, Cho $N$ et al. Breast mass evaluation: factors influencing the quality of US elastography. Radiology 2011; 259: 59-64

25 Mori M, Tsunoda H, Kawauchi $N$ et al. Elastographic evaluation of mucinous carcinoma of the breast. Breast Cancer 2012; 19: 60-63

26 Berg WA, Cosgrove DO, Dore CJ et al. Shear-wave elastography improves the specificity of breast US: the BE1 Multinational study of 939 masses. Radiology 2012; 262: 435-449

27 Cosgrove DO, Berg WA, Dore CJ et al. Shear wave elastography for breast masses is highly reproducible. Eur Radiol 2012; 22: 1023-1032 